\title{
7 \\ TECHNOLOGICAL TRAJECTORIES AND THE CLASSICAL REVIVAL IN ECONOMICS
}

\author{
Michael J.Piore
}

This chapter is part of a continuing effort to clarify and revise the argument which Charles Sabel and I originally put forward in The Second Industrial Divide (1984). It is a response to some of the criticism and interpretative commentary to which the book has been subject. At the same time, it is designed to draw attention to more recent developments in mainstream economics and suggest some of the connections between these mainstream developments and the French regulation school in terms of which our argument was initially conceived. The basic concern is how to understand and conceptualize economic growth and technological change.

\section{TECHNOLOGICAL TRAJECTORY}

The key notions upon which I want to focus are, first, that of a technological trajectory and, second, the two specific trajectories which in The Second Industrial Divide we term mass production and flexible specialization. The concept of a technological trajectory can be located quite precisely, in both the theory of regulation and the theory of mainstream economics, but the terminology implies a certain interpretation of these theories which many who associate themselves with these schools of thought might not accept.

In mainstream economics, a technological trajectory is the locus of the mystery surrounding economic growth. I use the term "mystery" because it seems to capture the essence of a story, possibly apocryphal, which I have always thought most basic to mainstream growth theory. The story is about Bob Gordon and Simon Kuznets, who were commentators for a panel of papers on economic growth at the annual meetings of the American Economic Association. Simon Kuznets was, of course, the father of national income accounting and, in a sense, invented growth measurement. Bob Gordon is a member of my arrogant generation, and the story took place at the time when we were at our most arrogant age. Bob, as the story goes, spoke first, and began by dismissing all the papers with the comment: "The problem of economic growth was solved by Griliches in his article of 19 ..." In the silence which ensued while the audience waited for him to continue, Kuznets rose from his chair, walked to the podium, gently put his arm around Bob's shoulders and said "Professor Gordon, you cannot solve the problem of economic growth."

In mainstream theory, the mystery of growth is that an industrial economy is able to generate progressively more output over time with the same resources. This effect is 
measured by Solow's residual - that, I imagine is what the Griliches' paper to which Bob referred "explained." In a crude sense, a technological trajectory is yet another attempt to penetrate that mystery. The criticism is that it, and the various specific trajectories identified in The Second Industrial Divide, are basically just a new terminology for the same old thing: they may be nice names, but they leave the mystery unresolved. This chapter can be read as an attempt to respond to that criticism.

In one respect the criticism is not well-taken. The terminology involves a lot of hand waving but it invokes at least one substantive proposition. It implies that there is a very specific growth process, so specific that it entrains very definite implications for the institutional structures of the economy. The valid criticism is that Sabel and I assert that relationship without specifying the growth processes in a way in which the institutional structures actually derive from them. The notion that there is a specific growth processa process so specific that one should be able to deduce the institutional characteristics of the economy from it-however, directly conflicts with a central (albeit implicit) assumption of neoclassical growth theory: that the sources of the residual are so various that they have no strong institutional implications. In the class of models which Solow pioneered, growth is the product of a vast multiplicity of little human actions. That growth is the impenetrable mystery. This view, however, is peculiar to neoclassical growth theory and is not universal to mainstream theory as a whole. Indeed, the most recent growth literature in mainstream economics coming out of Chicago, quite explicitly rejects this position. Its ambition is to formulate a theory with strong substantive implications. We turn to the question of how well it has thus far succeeded below.

The school of regulation is not a homogeneous approach to economic analysis either. What Sabel and I found interesting in the regulation approach was the marriage between the neoclassical lessons about an economy as a selfequilibrating system and the Marxist idea of an economy as evolving through history, generating tensions and conflicts, which were ultimately disequilibrating and were finally resolved through the political process. Defined in this way, as a marriage between neoclassical and Marxian approaches, the notion of a technological trajectory definitely belongs to the Marxian dimension: it is that set of forces which propels the economy through history, causing it to outgrow any particular regulatory framework and enter into crisis.

The idea that something quite specific propels the growth process is, of course, not simply Marxian. It was shared by the classical economists, beginning with Adam Smith, and is, as I have already noted, the central tenet of the classical revival at Chicago. In Marx, or at least among Marxians, there are a variety of distinct ideas about what it is that ultimately generates the historical thrust of the system. The major division is between those who see that thrust as rooted in some kind of natural evolution of the technology and those who see it as generated by class conflict. ${ }^{1}$ So long as there is only one technological trajectory, however, this distinction does not really matter: in the highly integrated process envisaged by Marx, they both lead to the same set of institutional outcomes. When one postulates, as we have, two trajectories, the outcome is open and the source of these trajectories becomes a central issue. In Marxian terms, a major criticism of The Second Industrial Divide is thus the failure to address it. But the flaw in the argument which leads to this reproach is essentially the same as when the argument is viewed from a mainstream perspective: the argument is about the way in which 
alternative technological trajectories generate particular institutional structures, but we fail to define the trajectories in a way in which the structure can be deduced from them.

Again, however, to say that The Second Industrial Divide defines a trajectory by the institutions with which it is associated is to concede too much. A good deal, in fact, is said about the trajectory of mass production, independently of its associated institutions. What is said makes the following assertions: first, the trajectory of mass production involves the search for growth (or technological innovation) through the process of the division of labor, as exemplified by Adam Smith in the transition from pin craftsman to pin factory. Second, growth of this kind has a set of distinct technical characteristics. The critical characteristics, in terms of the institutional structures of the economy are fourfold:

a) economies of scale within the firm,

b) increasing returns for the economy as a whole,

c) the specialization of productive resources and,

d) the divorce between conception and execution in production.

The technological trajectory of flexible specialization is not specified this precisely. We did, however, delimit the institutional forms associated with it. The organizational literature at that time, especially but not only in economics, distinguished two basic institutional forms: "hierarchies" exemplified by the large, vertically integrated corporation and "markets," where basic units were isolated small firms communicating through price signals in a market. We associated flexible specialization with a third institutional structure, one of a series of small (in relationship to the hierarchical corporation) units engaged in intense direct communication and embedded in a dense social network. Because there was relatively little research on this organizational form, we drew primarily on work on industrial districts in central Italy and upon old craft communities, generally characterized as "pre-industrial," which in most areas, had disappeared. There now exists a much more substantial body of work on what have come to be termed "network" organizations, and there is an emergent consensus in the management literature that this organizational form is often appropriate not only to organize relationships among small firms but also to structure the relationship among the internal units of large corporate enterprises and between the corporation and its suppliers, customers, and even its external competitors. But the question remains: what is the relationship between this network organization and the characteristics associated with the mass production trajectory? Is it responsive to the absence of all of those characteristics? Or merely some of them? If it does not generate growth through the division of labor, how is growth generated?

Before turning to discuss these questions, it is worth recognizing that what is said about mass production does clarify several issues in the current growth literature. First, it clarifies the relationship between flexible specialization and contemporary developments in organizational design and manufacturing technology associated with flexibility, to which flexible specialization is frequently linked. A number of the latter do not affect any of the basic characteristics of mass production. In particular, they maintain the distinction between conception and execution, they continue to rely on resource specialization, albeit in a somewhat novel way, and they seem to involve both substantial economies of scale and increasing returns. This difference led, in an earlier paper, to a distinction between 
flexible specialization and flexible mass production (Piore 1989). A given productive operation in the latter produces a gamut of products and is thus not dedicated to a single make and model as in classic mass production. But the variety is limited and the products specified in advance. In flexible specialization, by contrast, the product line is openended. This distinction also involves certain cognitive differences in the approach to the productive process, but the significance of these cannot be deduced from the list of characteristics defining mass production, and requires an expanded definition of flexible specialization, to which we turn below.

\section{Combining mass production and flexible specialization}

A second point which does emerge from the list of characteristics defining mass production is the basic difficulty of combining mass production and flexible specialization in a single system. To assert that growth under mass production involves increasing returns is to suggest that any alternative trajectory threatens its dynamism.

The essential idea of mass production is captured by Figure 7.1. That idea is that the economy moves down the curve, $a b$, over time; it does so by increasing output, through standardization of products. Smith pointed out that there was another method of production, craft production, which produced specialized goods but with stagnant technology, so that it always had cost $a$. The result: the consumer is faced with a choice, governed by the price differential between $\mathrm{P}_{c}-\mathrm{P}_{m}(1 / q)$, and $q$ grows over time.

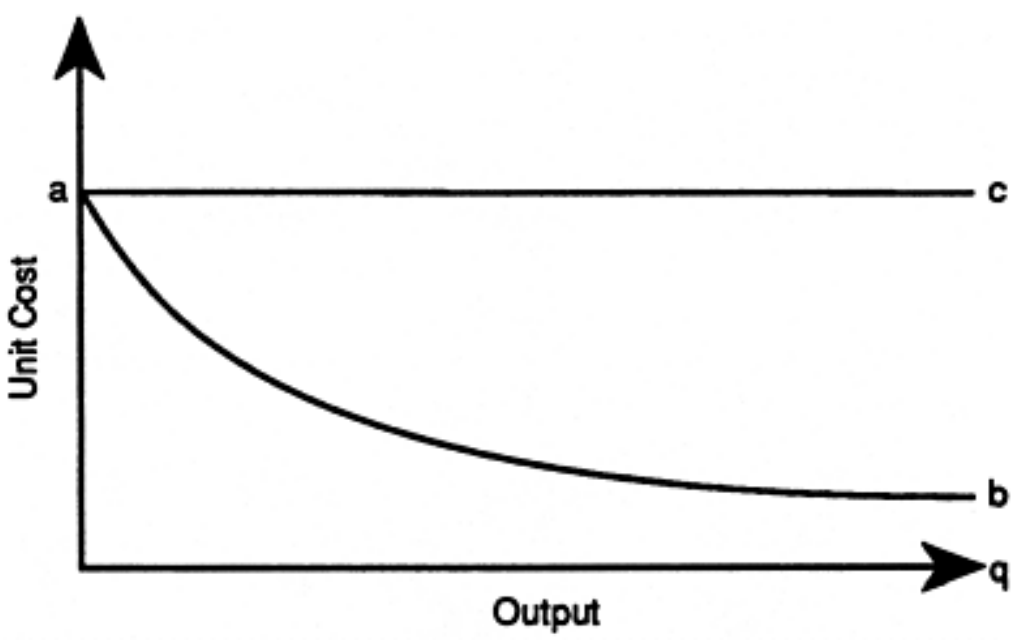

Figure 7.1 Mass production curve

The postulate about the emergence of flexible specialization as an alternative growth trajectory is that, at some point in the late $1970 \mathrm{~s}, \mathrm{P}_{\mathrm{c}}$ begins to fall due to a new dynamic of technological change. As it does so, $\mathrm{P}_{c}-\mathrm{P}_{m}$ declines, and customers are drawn away from mass markets, and $q$ falls. The fall in $q$, however, itself aggravates the process, raising $P_{m}$ and further narrowing the price differential. 
In analyzing these developments, one can make a further distinction between economies of scale associated with fixed investment in specialized resources and increasing returns associated with the technological development to which the specialization leads. The latter may be irreversible. In other words, the expansion of production may generate "new knowledge." Whether or not this is the case depends on the precise way in which specialization and technological innovation interact, a point to which we return below. If there is irreversibility, or some irreversibility, the technological gains may be preserved in smaller units and at least a part of the effects of a declining $q$ are reversed over time as the scale of new plant and equipment is adjusted to the reduced market size. Then, mass production will makes a resurgence, an effect which we currently seem to be observing. But our characterization of the mass production trajectory suggests that the resurgence will be temporary; the dynamism of mass production depends on the progressive expansion of $q$ and once the scale is adjusted, the technology will stagnate.

\section{Flexible specialization and the classical revival}

A further observation which one can draw from this characterization of mass production relates to the classical revival at Chicago (Lucas 1988). The classical revival, as we suggested earlier, has basically accepted the notion that there is a technological trajectory in the sense that we are using the term, i.e., a growth process that has substantive implications for the economic structure. But the literature assumes that this process is consistent with a competitive economic structure and the concern is with modeling that process as a kind of "general equilibrium" growth. Indeed, the competitive nature of the associated institutional structure is such a fundamental tenet of this literature that it is not even explicitly stated, let alone argued. What makes this curious is that the new Chicago literature draws upon exactly the same classical tradition that we use to define mass production. How does this happen? What is the difference?

In terms of the list of four defining characteristics, the difference centers on the distinction between increasing returns at the level of the economy and economies of scale at the level of the firm. We have defined mass production in a way in which the two characteristics are inextricably linked: you cannot have the former without the latter. And the Chicago literature assumes that the increasing returns for the economy do not imply economies of scale at the level of the firm. In the Chicago revival literature, increasing returns involve external economies. And Robert Lucas even coins the term "external human capital economies" to characterize the growth process. The key question then becomes: are the economies associated with the classical growth process external?

The idea that such economies are external comes from Marshall. But Chicago literature does not actually refer to Marshall himself; it tries to make this point instead by reference to Allyn Young (1928). In so doing, it confuses precisely those issues that we are attempting to highlight. The confusion arises because Young uses Adam Smith's pin factory to illustrate his argument. And, in the pin factory example, resources are too specialized to generate "external economies" of scale. Thus, Chicago would need to postulate an alternative trajectory in order to sustain its models. It need not as a matter of logic, of course, join the whole debate: it could simply assert that there is a single 
trajectory with the properties for which it is looking and that Smith (and Young) were either mistaken about what the pin factory growth process was or about its overwhelming importance. But given the extensive literature about network structures which is now developing, this may be a little harder to do than it was in the past.

Chicago might have gone back to Marshall, instead of Allyn Young, but this would not have solved the problem. There is now a very extensive literature trying to interpret exactly what Marshall observed in the light of contemporary experience. One influential branch of the literature argues that what Marshall observed was essentially akin to the dynamic industrial districts which emerged in Italy in the 1970s. Indeed, the very term "industrial district" is taken from Marshall's text (Becattini 1979). But the Italian industrial districts are not, as we have noted, markets: the intensity of communications which occurs within them and the social structures in which they are embedded makes it very unlikely that they could ever be compatible with a competitive price system (Piore 1990). Moreover, there is a real question about the "externality" of the economies associated with these kinds of network organizations. The research on both the network corporation and the Italian districts suggest that they survive and prosper only if the economies which are external to particular productive units are internalized as parameters in the decisions of some higher level organization unit, e.g., the corporate headquarters in large organizations; the municipal government, the trade union, and/or a business association in the geographic regions (Piore 1990).

My own reading of the literature is that Marshall did not observe industrial districts in the sense that this term is used in the network organization literature. I think that Allyn Young's choice of the pin factory example was indeed apt: that what Marshall observed might best be termed a dispersed hierarchy, i.e. a set of narrowly specialized and hierarchically coordinated productive units. These units operated like the mass production factory of the functionally divided corporation, but the relationships were organized by contracts rather than by internal rules. His observations call into question much of the new theory of the corporation, particularly that of Oliver Williamson and Alfred Chandler who argue that modern business forms are a response to economies of scale. But they are not associated with an independent growth trajectory; the economies of growth are internalized in contracts among these units just as they are in the vertically integrated corporation. Neither reading of Marshall suggests that he was observing a competitive market economy in the sense that we use that term in contemporary economics or that such an economy could sustain growth. To resolve the problem about the relationship between growth and Marshall to the classical economists themselves. organization form, it thus appears that one must go beyond Young and

\section{CLASSICAL GROWTH THEORY}

\section{Adam Smith}

The two key propositions of classical growth theory originate in Adam Smith:

1 growth is produced by the division of labor, and

2 the division of labor is limited by the extent of the market. 
But the classical growth process was actually defined by Adam Smith's pin factory example. Or rather, the classical growth process is defined by the example of the transition from the master pin-maker who made the whole pin to the factory in which "one worker pulls the wire, a second worker cuts the wire, a third worker heads the pin, a fourth points the pin, and so forth."

Why should the division of labor enhance productivity? There is a certain ambiguity in Smith here. The ambiguity is important, and we will return to it shortly. But the underlying reason is the specialization of productive resources: specially trained workers and specialized tooling.

The specialization leads directly to Smith's second proposition, that the division of labor is limited by the extent of the market. Because the resources are specialized, they cannot shift to alternative tasks. They become "inflexible" or inelastic. The specialization is thus justified only if labor and capital can be kept employed in the tasks which they are "specialized" to do.

This proposition about the extent of the market is an assertion about increasing returns: as the level of output expands, it becomes possible to further divide, and hence further specialize, productive resources. Must these increasing returns be internalized, i.e. do increasing returns manifest themselves as economies of scale at the level of the firm? Smith did not seem to see a connection: or, at least, he never identified the conflict between growth and competition which such firm level economies of scale imply. But modern human capital theory suggests that in the pin factory example the increasing returns must be internalized: the pin factory resources are not just specialized, they are specific; they can be used only in the particular pin-making task. By the time we reach the end point of this growth process in the automobile factory, the resources are specific to the make and model of a particular product. When the model changes, the worker must be retrained and the old equipment scrapped and replaced. Specific investments of this kind will not be made unless the firm can capture the returns. In the pin factory growth process, moreover, the market will never support the additional firms which would be required to eliminate the specificity of the investments: in a larger market, it will always pay to divide the tasks still further and make the resources still more specific. Increasing returns, economies of scale and resource specializations are thus inextricably linked. The Chicago-Marshallian growth process, like flexible specialization, requires a different growth mechanism.

\section{Marglin}

Clues for an alternative growth mechanism are offered by the debate about the relationship between the division of labor and productivity growth. Credit for opening, or rather reopening, that debate goes to Stephen Marglin and his 1974 article "What do Bosses Do?" (Marglin 1974). Marglin systematically reviews Smith's rationale for the pin factory and adduces evidence which suggests that each of the pieces of Smith's argument is either empirically false or quantitatively trivial. Marglin then argues that the division of labor is the product not of efficiency but of class conflict. It is designed to enhance the control of the bosses; it does not contribute to growth. Although it would constitute a considerable digression to engage Marglin's argument fully here, the 
argument is difficult to sustain. Its chief limitation for our purposes is that it offers no alternative growth theory: either growth is an illusion or, as it is for Kuznets, a mystery. The empirical evidence which Marglin offers suggests that the particular form of growth may have been chosen initially because it enhanced the power of the "bosses," and the attempt to alter the growth process may be resisted for that reason, but the evidence is consistent with the notion that the growth which results from the process is real enough. And, in fact, if one believes that growth to be real, the postulate of an alternative, but rejected growth trajectory, which we are seeking to sustain here, would only strengthen Marglin's assertions about the role of class conflict: the conflict might determine which of several alternative paths was chosen and/or why, once chosen, the commitment was maintained. To invoke class conflict in this way, one need not make growth itself an illusion. But, Marglin's criticisms of Smith, while cogent, are not helpful in the construction of an alternative theory of growth.

\section{Marx}

Much more helpful in this regard are the observations of Karl Marx, not the Marx of the class conflict, from which Marglin drew his inspiration, but the Marx of technological determinism. Marx's ideas about the efficacy of the division of labor and the enhancement of productivity are, at root, very different from Smith's and much closer to modern theories about cognition. Two of Marx's propositions appear particularly promising in terms of developing the notion of an alternative growth trajectory. One is the distinction which he draws between the social division of labor and the detailed division of labor. The second is the relationship which he develops between the detailed division of labor and mechanization. Marx makes a third observation about the rise of the factory system which is also suggestive.

\section{The social division and the detailed division}

The distinction between the social division of labor and the detailed division is essentially the distinction between the pin craftsman and the pin header.

Marx suggests that these are two distinct and technologically powerful developments. The pin craftsman - which Smith took as the starting point in the development processis actually itself a distinct technological development, involving the separation of pin making from the making of other products (like sheep-herding, cow tending, clothmaking, and the like) which were once all produced together in a self-contained household. The separation contributes to productivity because it isolates an activity with a distinct conceptual core, and by focusing on that core and understanding it better, one will produce better pins, possibly in a more effective way. The isolation of pin heading yields no such advantages, because pin heading is not a conceptually distinct operation; it has no meaning independent of pin making (Marx, Capital: 390).

\section{Reconceptualization}

Indeed, for Marx, the contribution of the detailed division of labor was very different. It 
enabled the production process to assimilate the logic of the machine. In this sense, it is virtually the opposite of the social division of labor. One separated out the task of pin heading in order to escape the conceptual apparatus of the pin and think of the task instead in terms of a rationale associated with machinery. Having done so, one is then able to mechanize the task of pin heading. A by-product of this process of technological development is the narrowly trained worker who does the "pin heading" before it is mechanized. This is an extremely important part of the story which Marx tells about capitalist development but it is not central to the issues here.

\section{Reintegration}

A third insight into the process of growth is suggested by Marx's comments on the factory system. For Marx, in contrast to Marglin, the factory system was a real engine of growth. But, Marx cautioned, the growth potential of the factory does not explain its development. The factory itself was created for one series of reasons: better to control a productive process and supervise a labor force which was previously dispersed under the putting out system; to share a common source of power, etc. Once the separate tasks were brought together under one roof and performed in proximity to each other, people were led to perceive of the productive process in new ways and this changed perception was itself a source of innovation. The new innovations were associated: they all facilitated the integration of the distinct operations. Thus, the innovations associated with the factory are different from those associated with mechanization: the latter involves looking at each operation separate from every other operation; the former involves looking at the operations in relation to each other (Marx, 414-5).

How might Marx's views enable us to understand the emergence of flexible specialization? Marx's observations can be read in at least three different ways. One reading is as a story about a dominant technology: the shift from handicraft production to machine production. The natural way to extend this story is to postulate a shift in the dominant technology. And, surely the new technology upon which one would want to focus is information technology, i.e., the computer. A second reading is that mass production grows out of a focus on the detailed division of labor, and that flexible specialization shifts the focus of technological change backward in the cognitive chain toward the social division of labor. A third reading might focus on the distinction between the fragmentation associated with the detailed division of labor and the integration associated with the factory. Innovation in flexible specialization seems more like the latter than the former.

It would be hard to reject any of these as explanations for contemporary patterns of technological change, and, indeed, although not presented in precisely those terms, much of the contemporary literature develops one or the other of these themes. But I would be inclined to abstract from Marx a fourth perspective, not necessarily inconsistent with the other three, but more abstract, more general: that technological innovation is a cognitive process and that one needs a cognitive theory to explain it.

The particular cognitive theory upon which Marx's own explanation of industrial progress is built is something like the following: technology is the embodiment of certain concepts or conceptual frameworks in terms of which we think about transforming 
resources. Each of those frameworks involves a set of abstract principles which tell us how resources can be organized and deployed. The ultimate foundation for technological progress involves the reorganization of our understandings in new, more revealing and hence, more powerful conceptual frameworks. But, in the meantime, there is a second process which involves applying the conceptual knowledge we already have to perfect existing technologies and organizations.

The social division of labor involves the organization of production into distinct, conceptually coherent groups of operations. This enables us to perfect the underlying technical know-how involved and apply it in more effective ways. Thus, for example, building and farming are conceptually distinct, and the separation of the two enables us to better concentrate on the development of the concepts appropriate to each. Similarly within building, carpentry and masonry involve conceptually distinct materials and, for this reason, we do better in each when we specialize in them as separate endeavors.

But the organization of knowledge in these ways has certain effects. One of these effects is that existing conceptual categories tend to limit the imagination. By directing attention in one way, they block alternative perspectives. In craft pin making, the production process is dominated by the logic of pins on the one hand and the human being on the other. Mechanization involves a different logic. In order to apply that logic, one needs to separate pin heading, for example, from the pin. The rationale for the detailed division of labor is thus different from the rationale of the social division. It is to escape one conceptual frame in order to move to another frame.

Finally, any partitioning of the production process into a distinct series of operations creates a problem of reintegration, and this problem arises in both the social division of labor and in the detailed division of labor. There are several different ways in which one might understand the issue of integration (or reintegration). One is that it is simply a mechanical byproduct of the process of partitioning: Marx's view of the development of the factory, however, implies that integration is more than this: that it is itself a distinct cognitive process. There are other clues in the literature that this is the case: a study by Persio Arida shows that innovation in automobile manufacturing oscillated historically between phases in which the major improvements involved the perfection of separate operations and phases where the improvements derived from achieving a better integration among operations (Arida 1977). This pattern is evident in a variety of technologies: for a period, IBM focused on perfecting individual machines while Digital's competitive advantage was achieved through systems. Audio-stereo technology seems to oscillate between periods where sales promotion focuses on the components individually and periods when the system as a whole is being hyped. The linguist Roman Jakobson calls the focus on the individual element metaphor and the focus on the sequencing of elements metonomy and, in studies of child speech development and of speech impairment in strokes known as aphasia, traces these different operations to separate and distinct parts of the brain.

But while integration appears to be a distinct cognitive process, there are certain dimensions of it which seem basically mechanical. First, in the detailed division of labor, the elements of the production process lose their original cognitive meaning in terms of the product. Indeed, the escape from the cognitive frame of the product is the purpose of the detailed division. This loss of independent cognitive meaning is what we mean by the 
divorce between conception and execution. It therefore leads to both the inflexibility (or rigidity) of task definition and to a strictly hierarchical organization in which the execution of the individual tasks is subordinated to a higher authority capable of reassimilating them into a cognitive frame in terms of which they have economic meaning.

In the social division of labor, the operations do not necessarily lose their economic meaning. But they might: in a social division of labor, one can make a further distinction between a partitioning of operations that maps directly onto the structure of consumption and a partitioning that does not. Examples of the former are such crafts as baking, tailoring, shoemaking, and, indeed, pin making. But the building trades are an example of a partitioning of operations in production which retains cognitive frames but does not map directly onto the structure of consumption: the carpenter, electrician, plumber, mason, etc. In the first set of crafts, the consumer performs the integration. In the latter case, the integration must be performed prior to consumption in the production process itself. This, I would like to argue, is the definition of flexible specialization. It achieves innovation through the tension between a deepening of understanding within a given cognitive frame and the pull to reintegrate back into a different frame in order to produce a sellable commodity. And it lends itself to a network structure.

This broad story can be reduced to a series of more sharply delimited propositions and summarized as follows:

1 Economic growth is the product of the division of labor.

2 The division of labor involves the partitioning of economic activity. One needs to understand both the cognitive and organizational implications of different partitioning principles.

3 The division of labor has two distinct dimensions: specialization and integration.

4 Cognitively, specialization has two distinct functions:

a The deepening of knowledge: the development of a deeper conceptual base, e.g., specializing in carpentry as a way of focusing on the properties of wood.

b Reconceptualization: a change in the conceptual frame itself.

5 Reconceptualization also has two dimensions:

a Transfer: the movement of an element from one conceptual frame to another, e. g., the mechanization of pin-heading.

b Invention: the creation of a new conceptual frame.

6 The problem of reintegration is created by a divergence between upstream conceptual categories and downstream conceptual categories, and especially a divergence between the categories in which production is organized and the categories of consumption.

\section{SUMMARY AND CONCLUSION}

To summarize and conclude: what I would like to suggest is that mass production 
involved growth through the detailed division of labor: growth through reconceptualization and within reconceptualization, primarily transfer. As a result of the transfer the conceptual categories in terms of which the elements of production were performed were distinct from the categories of the final product. This created a problem of reintegration, which led in turn to a hierarchical organization form.

Flexible specialization involves growth through the "social division of labor": the deepening of knowledge within given conceptual categories. But the partitioning of the productive process is different from the partitioning of the consumption process, and hence, there is a problem of reintegration, similar to the problem in mass production. Network structure facilitates both the deepening and the integration because, to integrate better with other conceptual specialties, the specialists are forced to develop their own specialty more fully. The conceptual level of understanding in this form of growth permits horizontal coordination, thus avoiding hierarchy, but the degree of interaction across specialties is too intense to permit a market.

The market organization of the kind which the Chicago School envisages would seem to be more likely when the conceptual structure of production maps directly onto the conceptual structure of consumption. Why this should ever be the case, however, is unclear. 